\title{
Darkening of white hair in Parkinson`s disease during use of levodopa rich Mucuna pruriens extract powder
}

\section{Escurecimento do cabelo branco na doença de Parkinson durante tratamento com extrato em pó de Mucuna pruriens rico em levodopa}

Renato P Munhoz', Hélio A G Teive²

An 85-year-old patient with stable Parkinson's disease (PD), treated with levodopa/carbidopa 250/25 mg tid. During a follow-up visit, it was noticed that her temporal white hair was getting progressively darker (Figure), starting after introduction of Mucuna pruriens extract (MPE) at a dose equivalent to $1000 \mathrm{mg}$ of levodopa/day. Hair and beard darkening was recognized as a complication of treatment with levodopa in PD since its earliest introduction. ${ }^{1}$ DOPA/dopamine are intermediate metabolites in the production of melanin, therefore, this association is not surprising. After the addition of decarboxylase inhibitors, this phenomenon, probably related to peripheral effects of levodopa, became strikingly rare.

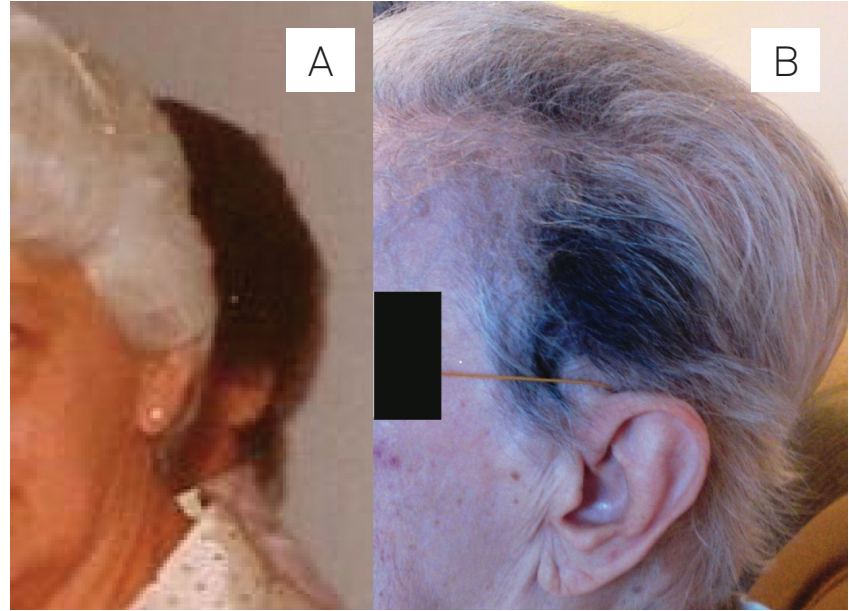

Figure. (A) The patient at the age of 62 year; (B) Showing hair darkening after use of Macuna Pruriens extract powder.

References

1. Reynolds NJ, Crossley J, Ferguson I, Peachey RD. Darkening of white hair in Parkinson's disease. Clin Exp Dermatol 1989;14:317-318. 